\title{
MAPEAMENTO DA ESCRITURA EM LÍNGUA PORTUGUESA COMO L2 DE SURDOS BRASILEIROS CANDIDATOS AO CURSO DE LICENCIATURA EM LETRAS EM LÍNGUA BRASILEIRA DE SINAIS
}

\author{
Cleide Emília Faye Pedrosa ${ }^{1}$
}

\begin{abstract}
Resumo
Como professora de Linguística do curso de Licenciatura em Letras Libras (Língua Brasileira de Sinais), tive a experiência de participar da elaboração e correção das provas de interpretação em LP (Língua Portuguesa) e das redações em LP nos vestibulares de 2015-2017, na Universidade Federal de Sergipe, no Brasil. Tal experiência motivou o desenvolvimento de projetos de pesquisa, entre eles: "Estudos das identidades e processos de escritura em língua portuguesa como L2: comunidade surda em pauta", com um plano de iniciação científica que focava na análise de redações de vestibular de Surdos. Diante dessa experiência, o objetivo deste estudo é mapear as estratégias linguístico-discursivas desenvolvidas por Surdos através de suas escrituras em língua portuguesa como L2. Como caminhos metodológicos na linha qualitativa-interpretativista, selecionamos uma representação de redação dos anos 2014-2017 da Universidade Federal de Sergipe. Os estudos são orientados pela análise linguística e discursiva, com forte influência da leitura social da Análise Crítica do Discurso (ACD) (FAIRCLOUGH, 2008; BESSA, 2016, PEDROSA, 2016) em complementaridade com os Estudos Surdos, sob a visão educacional e linguística. Como resultado tem-se que os textos e o mapeamento de suas materialidades funcionam como pistas que nos conduzem a refletir acerca de como ocorrem e ocorreram as práticas discursivas e sociais na educação de surdos e na construção de sua(s) identidade(s), especialmente a linguística, como um povo que é obrigado a ser bilíngue em sua própria terra por imposição majoritária dos ouvintes.
\end{abstract}

Palavras-chave: Língua Portuguesa como L2. Estratégias linguístico-discursivas. Surdos. Análise Crítica do Discurso. Estudos Surdos.

\section{MAPPING OF PORTUGUESE WRITING AS A SECOND LANGUAGE OF BRAZILIAN DEAF APPLICANTS TO BRAZILIAN SIGN LANGUAGES GRADUATION}

\begin{abstract}
As a Linguistics professor of the Libras (Brazilian Sign Language) graduation, I had the experience of participating in the elaboration and correction of the tests of interpretation in PL (Portuguese Language) and of the essays in PL in 2015-2017 entrance exams at the Federal University of Sergipe, Brazil. This experience led to the development of research projects, including: "Studies of the identities and processes of writing in Portuguese as a Second Language: deaf community on the agenda", with a scientific initiation plan that focused on the analysis of deaf people's entrance exams. Given this experience, the purpose of this

\footnotetext{
${ }^{1}$ Universidade Federal de Sergipe (UFS), São Cristóvão - Sergipe - Brasil. Doutora em Letras pela Universidade Federal de Pernambuco (UFPE). Pós-doutorado em Letras (UERJ, 2008). Investigadora visitante (Faculdade de Letras da Universidade de Lisboa, 2019-2020). É professora do curso de Letras Libras (Língua Brasileira de Sinais) e do Programa de Pós-Graduação em Letras, da Universidade Federal de Sergipe (UFS). E-mail: cleideemiliafayepedrosa@gmail.com
} 
presentation is to map the linguistic-discursive strategies developed by deaf people through their writing tests in Portuguese as a Second Language. As methodological paths in the qualitative-interpretative line, we selected a writing representation of the years $2014-2017$ from the Federal University of Sergipe, Brazil. These studies will be guided by linguistic and discursive analysis, with a strong influence of the social reading of Critical Discourse Analysis (CDA) (FAIRCLOUGH, 2008; BESSA, 2016, PEDROSA, 2016) in complementarity with Deaf Studies, under the educational and linguistic view. As a result, the texts and the mapping of their materiality serve as clues that lead us to reflect on how discursive and social practices occur and occurred in deaf education and in the construction of their identity(s), especially the linguistic ones, as a people who are obliged to be bilingual in their own land by majority imposition of hearing people.

Keywords: Portuguese as a second language. linguistic-discursive strategies. Deaf People. Critical Discourse Analysis. Deaf Studies.

\section{INTRODUÇÃO}

Como professora de Linguística e coordenadora (2014-2016) do curso de Licenciatura em Letras Libras (Língua Brasileira de Sinais), tive a experiência de participar da elaboração, do acompanhamento da tradução para Libras, da aplicação e da correção das provas de interpretação em Língua Portuguesa (LP) e das redações em LP nos vestibulares de 2015-2017, na Universidade Federal de Sergipe (UFS). Tal experiência nos motivou a desenvolver projetos de pesquisa, entre eles: "Estudos das identidades e processos de escritura em língua portuguesa como L2: comunidade surda em pauta" ${ }^{2}$, com um plano de iniciação científica que focava na análise de redações de vestibular de Surdos. Diante dessa experiência, o objetivo deste artigo é mapear as estratégias linguístico-discursivas desenvolvidas por Surdos através de suas escrituras em língua portuguesa como L2.

O percurso do texto exporá o diálogo entre as áreas da Análise Crítica do Discurso, da Gramática Sistêmico-Funcional e dos Estudos Surdos. Em seguida, será feita a análise do material, seguindo o objetivo proposto; e, por fim, serão traçadas algumas conclusões plausíveis.

2 DE MÃOS DADAS PARA A LEITURA LINGUÍSTICO-SÓCIO-DISCURSIVA DAS PRODUÇÕES ESCRITAS DOS SURDOS: ANÁLISE CRÍTICA DO DISCURSO, ESTUDOS SURDOS E GRAMÁTICA SISTÊMICO-FUNCIONAL

\footnotetext{
${ }^{2}$ Agradecemos à bolsista de IC, Débora Diniz, pela digitalização e digitação do corpus da pesquisa.
} 


\section{Linguagens - Revista de Letras, Artes e Comunicação - ISSN 1981- 9943 \\ Blumenau, v. 12, n. 3, p. 456-473, set./dez. 2018. \\ DOI: http://dx.doi.org/10.7867/1981-9943.2018v12n3p456-473}

Se considerarmos somente a perspectiva de língua defendida pela Gramática SistêmicoFuncional (GSF), isso já seria suficiente para termos uma visão social do uso da língua; contudo, se acrescentarmos o posicionamento da leitura social crítica da Análise Crítica do Discurso (ACD), o estudo ganha profundidade e compromisso político com o grupo vulnerável em estudo: o Povo Surdo.

Para Wodak e Meyer (2015), os fundamentos dos estudos críticos do discurso encontram-se na antropologia, na psicologia social, na retórica, na linguística do texto, na sociolinguística e na linguística aplicada, entre outros campos. Com base em Van Dijk (2008), os autores apontam que, entre as décadas de 1960 e 1970, "surgiram novas disciplinas estreitamente relacionadas nas ciências humanas e sociais" (VAN DIJK, 2008 apud WODAK; MEYER, 2015, p. 02). Esse é, pois, um traço transdisciplinar da ACD, o atravessamento de fronteiras epistemológicas.

Desde o final da década de 1980, pioneiros, na constituição da ACD, chamaram atenção para a influência das ciências sociais nos estudos relacionados às mudanças sociais (economia, política, cultura). Nesses contextos, a linguística pode dar grandes contribuições, visto que aceitamos que as interações e os processos "são cada vez mais linguisticamente mediados" (VIEIRA; MACEDO, 2018, p. 71).

Ressaltamos, no entanto, que, para a $\mathrm{ACD}$, a investigação linguística não se encerra em si mesma, considerando-se que a prática social advém desse estudo. Os vários pesquisadores em ACD podem variar nos diálogos teóricos que estabelecem ou nas correntes que seguem (entre eles: Dialético relacional, de Fairclough; Sociocognitiva, de Van Dijk; Histórica, de Wodak). Porém, entre as sete dimensões apontadas por Wodak e Meyer (2015, p. 02), que unem os analistas críticos em suas várias abordagens, apontamos, literalmente, neste artigo, as seguintes:

\footnotetext{
- O estudo das funções dos contextos (sociais, culturais, situacionais e cognitivos) do uso da linguagem.

- Análise de um vasto número de fenômenos de gramática de texto e uso da linguagem: coerência, anáfora, tópicos, macroestruturas, atos de fala, interações, tomada de turnos, sinais, polidez, argumentação, retórica, modelos mentais e muitos outros aspectos do texto e discurso (WODAK; MEYER, 2015, p. 02).
}

Para os analistas críticos, é fundamental constatar "como as práticas linguísticas, discursivas e sociais se inter-relacionam nas estruturas sociais" (PEDROSA, 2016, p. 71) a fim de tomar posição para “desvelar como estas estão alicerçadas em práticas ideológicas, de tal 


\section{Linguagens - Revista de Letras, Artes e Comunicação - ISSN 1981- 9943 \\ Blumenau, v. 12, n. 3, p. 456-473, set./dez. 2018. \\ DOI: http://dx.doi.org/10.7867/1981-9943.2018v12n3p456-473}

forma que se tornasse até difícil fugir delas" (PEDROSA, 2016, p. 71). Acerca desse aspecto, Bessa (2016) fala sobre a ênfase que se deve dar ao papel social com a linguagem, sob o ponto de vista do ensino de línguas maternas e estrangeiras. Entende ele que a disciplina Língua Portuguesa desde o ensino fundamental necessita "trilhar um caminho reflexivo e crítico quanto ao uso da própria língua e suas implicações" (BESSA, 2016, p. 135). Dessa forma, o desenvolvimento das pesquisas em ACD ajuda com o desenvolvimento no ensino.

Se considerarmos o conhecimento como um bem imaterial (BOURDIEU, 1998, p. 2013) e o conhecimento linguístico como um desses capitais imateriais, então quais as competências linguísticas dos surdos em LP? E o que a falta dessas competências pode gerar para o Povo Surdo? Esse conjunto de questões de "interdependência entre o poder social e a linguagem é um tópico contínuo e persistente" (WODAK; MEYER, 2015, p. 12) não apenas nos Estudos Críticos do Discurso, como também na sociologia e na sociolinguística.

Em resumo, a ACD tem o comprometimento de desvelar estruturas sociais tanto opacas quanto transparentes de dominação, poder e controle de grupos poderosos contra grupos vulneráveis e como esse controle se manifesta nos discursos. Daí se origina seu objetivo primordial: pesquisar a desigualdade social e a forma como ela é expressa em discursos legitimadores a fim de promover a equidade social.

\subsection{EDUCAÇÃO DE SURDOS: ENFRENTAMENTOS PARA UMA EDUCAÇÃO FORMAL}

Recuperar a história educacional dos povos surdos não é tarefa fácil. A que data devemos remontar, a que métodos, a que tipos de escolas? E todas essas e outras questões envolvem apenas a educação formal dessa comunidade.

Como plataforma inicial, concordamos com Garé (2016, p. 55) quando justifica, em sua pesquisa, que "adota-se o termo 'contexto formal' para diferenciar um lugar de ensinoaprendizagem orientado por uma proposta curricular, sendo esta, por sua vez, entendida como lugar de práticas pedagógicas”.

O livro de Bonet (1620) anunciava, em seu título, a proposta formal de ensinar os surdos a falarem - "Reduction de las letras y arte para enseñar a ablar los mudos"3. Seguindo apenas um mapeamento de sua obra, que é dividido em dois livros (duas partes, chamadas de livros),

\footnotetext{
3 “Redução das letras e a arte para ensinar os mudos a falar" (tradução nossa).
} 


\section{Linguagens - Revista de Letras, Artes e Comunicação - ISSN 1981- 9943 \\ Blumenau, v. 12, n. 3, p. 456-473, set./dez. 2018. \\ DOI: http://dx.doi.org/10.7867/1981-9943.2018v12n3p456-473}

observamos que, no livro I, o autor descreve a origem de cada letra do alfabeto latino, enquanto o livro II é mais dedicado aos surdos. Contudo, quando chegamos à história dos surdos a partir do material de Strobel (2009), verificamos a informação de que Ramirez de Carrión foi injustiçado por não receber mérito, à semelhança do que ocorreu com Bonet por sua publicação de 1629, sob o título: "Maravillas de Naturaleza en que se contienen dos mil secretos de cosas naturales, dispuestos por abecedario a modo de Aforismos fáciles, y breves, de mucha curiosidad y provecho, recogidos de la lección de diversos, y graves Autores" ${ }^{4}$ (RAMIREZ CARRION, 1629).

Essas duas obras são indicadas como pioneiras para a instrução dos surdos e fazem parte do repertório da história de sua educação formal. Em relação aos métodos utilizados nessa instrução, destacamos que na segunda metade do século XVIII, os educadores que aparecem primeiramente nesse cenário são Heinicke e L’Epee. O primeiro, pastor da escola alemã, defendia veementemente o método da oralização, enquanto o segundo, abade da escola francesa, era defensor do método combinado (ROCHA, 2008). O método da oralização acreditava que era necessário que os surdos oralizassem à semelhança dos ouvintes a fim de serem aceitos socialmente. Já o método combinado, pressupunha que se utilizasse tanto a língua de sinais, já conhecida dos surdos, quanto a fala.

Outro grande nome, também inserido nesses estudos, é o de Edward Miner Gallaudet (1837-1917), e uma excelente referência é sua publicação de 1868, American and European systems of deaf-mute instruction compared ${ }^{5}$. Nela, após visita à Europa, o autor estabeleceu comparação entre os estudos feitos naquele continente e nos Estados Unidos. Nas visitas às escolas europeias, ele procurou verificar o uso dos dois métodos referenciais: oralismo e combinado. Como resultado, constatou que ambos os métodos são utilizados em alguns lugares com ênfase na articulação e noutros com forte rejeição desse método; no entanto, revelou o autor que há instituições que tentam a harmonização e a combinação dos "métodos outrora

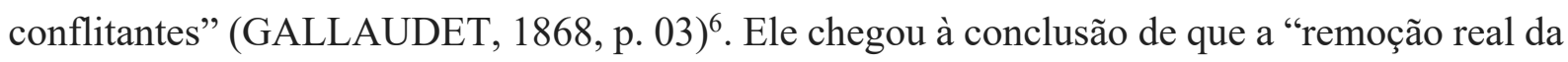
aflição do surdo-mudo pode ser vista apenas nas mãos" (GALLAUDET, 1868, p. 08) 7 .

\footnotetext{
4 "Maravilhas da natureza que contêm dois mil segredos de coisas naturais, dispostos em ordem alfabética como aforismos fáceis, e curtos, de grande curiosidade e proveito, coletados da lição de vários e sérios autores" (tradução nossa).

5 "Sistemas Americano e Europeu de Educação de surdos-mudos comparados" (Tradução de Tamires Cruz).

6 “(...)the once conflicting methods."

7 " The actual removal of the affliction of deaf-dumbness may be looked for only at the hands."
} 


\section{Linguagens - Revista de Letras, Artes e Comunicação - ISSN 1981- 9943 \\ Blumenau, v. 12, n. 3, p. 456-473, set./dez. 2018. \\ DOI: http://dx.doi.org/10.7867/1981-9943.2018v12n3p456-473}

Na mesma época, também houve a movimentação educacional para surdos no Brasil. Tudo se inciciou quando E. Huert, surdo e educador do Instituto de Surdos de Paris, manifestou, em 1855, através de carta a D. Pedro II, interesse em criar uma escola de surdos no Brasil. É importante salientar que a educação de surdos no Brasil, e mesmo em outras partes do mundo, não visava formar "letrados", mas "regenerar uma classe inteira de seres desgraçados muito tempo abandonados, pô-los na posse de uma instrucção impossível de adquirir de qualquer outro modo, por meio de methodo especial, restitui-los à sociedade, à sua família" (ALMANAK LAEMMERT, 1859, p. 478 apud SOFIATO; REYLI, 2011, p. 626).

"Regenerar" - era a filosofia para a educação dos "surdos-mudos" em sua trajetória entre nós. Felizmente, porém sem velar alguns retrocessos, podemos indicar que ocorreram avanços, desde 1856, com a criação do Colégio Nacional para Surdos-Mudos de Ambos os Sexos, conhecido, atualmente, como Instituto Nacional de Educação de Surdos (INES) (ROCHA, 2008). O Instituto se tornou a mais forte referência no acolhimento desta comunidade, com grande avanço da sua pauta educacional, já que foi de um colégio para "salvar os regenerados" a um Instituto com currículo similar ao das escolas "regulares" de ouvintes, sob a perspectiva do ensino bilíngue para surdos.

No contexto de sua educação formal bilíngue, os surdos também encontram o desafio de aprender o Português escrito. Sobre este desafio se debruçam vários professores e pesquisadores. São muitas orientações quanto a esta metodologia, resultantes de erros e acertos de práticas pedagógicas e das pesquisas das áreas que norteiam essa aprendizagem (BROCHADO, 2003; NEVES, 2017). Ainda sobre o assunto, leitores podem encontrar bons resultados de investigações nos trabalhos de Souza (2015) e Silva (2016).

Em 2003, Brochado defendeu a tese "A apropriação da escrita por crianças surdas usuárias da língua de sinais brasileira”. Nela, a autora elencou algumas características da escrita surda, dependendo do nível e da fase de aprendizagem da língua portuguesa como L2, embora tenha reconhecido, no processo, que os "estágios sucessivos do conhecimento linguístico", pelos surdos, "revelam que a linguagem dos aprendizes varia" e que estes se utilizam de algumas "estratégias de transferência da língua materna", de aspectos internos, ou seja, individuais; e também de aspectos externos, tais como "a competência do professor, a adequação de metodologia e dos materiais didáticos" (BROCHADO, 2003, p. 308).

A seguir, a autora procedeu a um levantamento dos processos identificados em sua pesquisa, dos quais reproduzimos alguns, mas adaptados em um quadro nosso: 


\section{Linguagens - Revista de Letras, Artes e Comunicação - ISSN 1981- 9943 \\ Blumenau, v. 12, n. 3, p. 456-473, set./dez. 2018. \\ DOI: http://dx.doi.org/10.7867/1981-9943.2018v12n3p456-473}

Quadro 01. Resumo dos estágios do conhecimento linguístico e estratégias de transferência da língua materna.

\begin{tabular}{|c|c|c|}
\hline INTERLÍNGUA I (IL1) & INTERLÍNGUA II (IL2) & INTERLÍNGUA III (IL3) \\
\hline $\begin{array}{l}\text { Nesse estágio, observamos o } \\
\text { emprego predominante de } \\
\text { estratégias de transferência da } \\
\text { língua de sinais (L1) para a } \\
\text { escrita da Língua Portuguesa } \\
\text { (L2) desses informantes, } \\
\text { caracterizando-se por: } \\
\text {. predomínio de construções } \\
\text { frasais sintéticas; } \\
\text {. estrutura de frase muito } \\
\text { semelhante à Língua de Sinais } \\
\text { Brasileira (L1), apresentando } \\
\text { poucas características do } \\
\text { Português (L2). }\end{array}$ & $\begin{array}{l}\text { Nesse estágio, constatamos na } \\
\text { escrita de alguns alunos uma } \\
\text { intensa mescla das duas línguas, } \\
\text { em que se observa o emprego de } \\
\text { estruturas linguísticas da Língua } \\
\text { de Sinais Brasileira e o uso } \\
\text { indiscriminado de elementos da } \\
\text { Língua Portuguesa, na tentativa } \\
\text { de apropriar-se da língua alvo. } \\
\text { Emprego, muitas vezes, } \\
\text { desordenado de constituintes da } \\
\text { L1 e L2, como se pode notar: } \\
\text { justaposição intensa de } \\
\text { elementos da L1 e da L2; } \\
\text { - estrutura da frase ora com } \\
\text { características da Língua de } \\
\text { Sinais Brasileira, ora com } \\
\text { características da frase do } \\
\text { Português. }\end{array}$ & $\begin{array}{l}\text { Nesse estágio, os alunos } \\
\text { demonstraram na sua escrita o } \\
\text { emprego predominante da } \\
\text { gramática da Língua Portuguesa } \\
\text { em todos os níveis, } \\
\text { principalmente no sintático. } \\
\text { Definindo-se pelo aparecimento } \\
\text { de um número maior de frases na } \\
\text { ordem SVO e de estruturas } \\
\text { complexas, caracterizam-se por } \\
\text { apresentar: } \\
\text { estrutura da frase na ordem } \\
\text { direta do Português. }\end{array}$ \\
\hline
\end{tabular}

Fonte: elaborado com base em Brochado (2003, p. 308-310).

Outra investigadora, a Neves (2017), em sua pesquisa de doutorado "Educação bilíngue para surdos e as implicações para o aprendizado da Língua Portuguesa como segunda língua", defende a tese da importância do contexto bilíngue para o aprendizado da Língua Portuguesa como segunda língua e com metodologia própria para surdos, e destaca também a necessidade de que a língua de instrução seja a Libras. Abaixo, um quadro demonstrativo do desenvolvimento dos alunos.

Quadro 02. Exemplos de transferência interlinguística

\begin{tabular}{|l|l|l|l|l|}
\hline Participantes & Frase & $1^{\text {a }}$ Produção & Aspecto & $2^{\text {a }}$ Produção \\
\hline P3 & Suco o bebi eu & Eu suco o bebi & Ordem das palavras & Eu bebi o suco \\
\hline P6 & Lápis apontei eu & Eu lápis apontei & Ordem das palavras & Eu apontei o lápis. \\
\hline
\end{tabular}

Como contextualizamos anteriormente, a leitura social crítica da ACD e da Gramática Sistêmico-Funcional (GSF) conjugam esforços para uma leitura compromissada e politicamente engajada em prol de grupos vulneráveis, assim, no próximo tópico, nos compete expor alguns princípios da GSF. Este será direcionado a fim de que possamos fazer uma análise linguística discursiva do material escrito em LP como L2 e acrescentando a base dos achados, principalmente, a partir de Brochado (2003). 


\subsection{O PAPEL FUNCIONAL DA LÍNGUA: GRAMÁTICA SISTÊMICO-FUNCIONAL}

Embora o termo funcionalismo em Linguística evoque uma dicotomia com o termo formalismo, esses "não são, de todo, termos dicotómicos", assevera Gouveia (2006, p. 428), pois, o funcionalismo reconhece a necessidade das "formas", embora não as priorize. Isso porque a "principal tarefa da linguística é explicar o papel que a língua desempenha na cultura e no mundo social" (GHIO; FERNÁNDEZ, 2005, p. 05). Entre algumas escolas funcionalistas, estudamos a Linguística Sistêmico-Funcional (LSF), a Gramática Sistêmico-Funcional (GSF) ${ }^{8}$.

A década de 1960 marca o início da trajetória da Linguística Sistêmico-Funcional na Europa, porém, é a partir da década de 1980 que ela influencia as pesquisas linguísticas no Brasil (VIAN JR.; DE SOUZA, 2017). No entanto, é somente a partir de 2017, que nós, como pesquisadores, procuramos associar esta gramática descritiva aos Estudos Surdos. O interesse em aplicar a GSF aos estudos sobre a escritura do Povo Surdo é sustentado pelo fato de o próprio Halliday (2004), iniciador desta proposta de LSF, trazer a premissa de que essa teoria nos ajuda a compreender a linguagem/língua dos surdos.

Desse modo, embasados numa semântica discursiva, podemos nos esforçar para entender a escritura dos surdos ao utilizarem a LP como L2, sua especificidade ao produzirem, em muitos casos, "um português surdo", e isso ou com forte influência da gramática da língua de sinais, ou tão somente pelo uso intuitivo de sua língua, já que são poucos os que têm conhecimento mais formal da gramática da Libras.

Sob tais perspectivas, os contextos de cultura e de situação serão imprescindíveis para a compreensão do que os significados expressam em um texto/discurso. Assim, teoricamente, a GSF é arquitetada com três descrições primordiais (VIAN JR.; DE SOUZA, 2017, p. 188):

(1) há uma relação dialética entre a língua e o contexto em que é produzida. O contexto abrange um contexto de cultura (gênero) e um contexto de situação (registro); (2) a língua apresenta-se organizada para uso em três estratos: o grafofonológico, o lexicogramatical e o semântico-discursivo; (3) três metafunções estão presentes em qualquer ocorrência de comunicação: ideacional, já que ideias, pensamentos, sentimentos e toda sorte de emoções são expressadas; interpessoal, uma vez que essas expressões ocorrem na interação com outros; e textual, pois tudo que é expresso é organizado em texto.

\footnotetext{
${ }^{8}$ A LSF trabalha com categorias de macro e de microfunções. De um modo geral, aceita-se que, quando trabalhamos com microfunções, fazemos menção à Gramática Sistêmico-Funcional (GSF); quando com macrofunções, fazemos referência à LSF.
} 
Há, para cada metafunção, realizações gramaticais por meio de sistemas: o de transitividade, ligado à metafunção ideacional; o de modalidade, ligado à metafunção interpessoal, e, por fim, o sistema de tema, ligado à metafunção textual (VIAN JR.; DE SOUZA, 2017).

Nesta pesquisa, descreveremos, de maneira geral, como se manifestam os estratos grafofonológico, lexicogramatical e semântico-discursivo no corpus investigado.

\section{METODOLOGIA PARA UMA ANÁLISE LINGUÍSTICO-DISCURSIVA}

Os estudos serão orientados por uma metodologia qualitativa-interpretativista, considerando-se a análise linguístico-discursiva, com forte influência da leitura social da Análise Crítica do Discurso (ACD) (PEDROSA, 2016, 2018) em complementaridade com os Estudos Surdos, sob a visão de uma linguística educacional.

Para atender ao objetivo de mapear as estratégias linguístico-discursivas desenvolvidas por Surdos através de suas escrituras em Língua Portuguesa como L2, selecionamos uma representação de redações produzidas nos anos de 2014 a 2017, para acesso ao curso superior de licenciatura em Letras Libras, da Universidade Federal de Sergipe, Brasil.

Apontaremos algumas estratégias linguístico-discursivas identificadas em textos escritos de candidatos surdos ao ingresso no curso superior a partir dos seguintes blocos: (A) estrato grafofonológico; (B) estrato lexicogramatical; (C) estrato semântico-discursivo. Os estratos podem receber subdivisões, se for necessário. Para efeito de análise e metodologia, seguiremos uma tentativa de análise em separado, embora saibamos que os estratos ocorrem simultaneamente. Poderíamos utilizar os mesmos fragmentos para exemplificar os estratos; porém, preferimos variar a fim de que ofereçamos mais exemplos da escritura do "portuguêssurdo".

A identificação do material coletado será através de um número utilizado exclusivamente para este artigo, a fim de respeitar o anonimato, seguido da referência ao curso de Letras Libras (LL) da Universidade Federal de Sergipe (UFS), bem como ao ano correspondente de 2014-2017.

\section{MAPEAMENTO DAS ESTRATÉGIAS LINGUÍSTICO-DISCURSIVAS DA ESCRITURA SURDA EM LÍNGUA PORTUGUESA COMO L2}




\section{Linguagens - Revista de Letras, Artes e Comunicação - ISSN 1981- 9943 \\ Blumenau, v. 12, n. 3, p. 456-473, set./dez. 2018. \\ DOI: http://dx.doi.org/10.7867/1981-9943.2018v12n3p456-473}

Considerando o objetivo desta pesquisa, buscaremos reconhecer, nas redações de 2014 a 2017, quais estratégias os candidatos surdos utilizaram para produzir seus textos. Sobre as temáticas dessas produções, sempre exploradas com base em textos motivadores, temos o seguinte: em 2014, foi pedido que o candidato defendesse sua posição acerca da inserção de surdos no contexto escolar: inclusão escolar ou escola bilíngue; em 2015, os candidatos tiveram de escrever um texto defendendo sua posição sobre se o ensino de LP para surdos deveria sofrer adaptações ou se as estruturas deveriam ser ensinadas sem adaptações; já em 2016 a prova solicitou a opinião dos candidatos sobre cortes de verba na educação; e, em 2017, os inscritos tiveram de produzir um texto dissertativo-argumentativo com a temática Educação à Distância. Ressaltamos que as temáticas das provas são igualmente para surdos e ouvintes inscritos na seleção.

Vamos aos estratos e aos exemplos selecionados para análise:

\section{(A) Estrato grafofonológico}

No caso da amostra, analisaremos o estrato sobre a grafia dos candidatos surdos e sublinharemos alguns termos que caracterizam o "Português-surdo". Na exposição de Ghio e Fernández (2005), podemos entender o estrato grafofonológico da seguinte forma: "La fonología es un recurso para realizar las expresiones verbales abstractas como sonido e incluye la entonación, el ritmo y la articulación silábica y fonética”. Contudo, chamam atenção que “alternativamente, este nível puede ser el sistema gráfico de una lengua. En general, el sistema de la fonología se relaciona de manera arbitraria o puramente convencional con la léxicogramática" (FERNÁNDEZ , 2005, p. 58)9.

Exemplos:

1- Surdos não tem condições inclusão escolar porque professores não língua de sinais também interprete nada, surdos esta triste tambem mal, mas eles alunos ouvir aprende desenvolmento [...] UFS/2014).

As aulas no ensinar libras repeita os surdos conseguir desenvolvimento escola Bilíngue (01 LL-

2- Escola alunos ouvir confisão muito surdos, também não conseguir comunica [...] (01 LL-UFS/2014).

\footnotetext{
9 "A fonologia é um recurso para a realização de expressões verbais abstratas como o som e inclui entonação, ritmo e articulação silábica e fonética." Contudo, chamam atenção que "alternativamente, esse nível pode ser o sistema gráfico de um idioma. Em geral, o sistema de fonologia se relaciona de maneira arbitrária ou convencional com o léxico-gramática" (Tradução nossa).
} 


\title{
Linguagens - Revista de Letras, Artes e Comunicação - ISSN 1981- 9943 \\ Blumenau, v. 12, n. 3, p. 456-473, set./dez. 2018. \\ DOI: http://dx.doi.org/10.7867/1981-9943.2018v12n3p456-473
} UFS/2015).

3- As crianças ver nunca o escola nova, quero aula vou prescia apender importante [...] (02 LL-

Devido à falta do apoio fonológico, torna-se muito difícil memorizar todos os fonemas que constituem as palavras em uma língua oral. Qual a função de um acento em uma palavra para um surdo, como na palavra "interprete"? Outro desafio é o tamanho das palavras, vejamos, por exemplo, o tamanho da palavra "desenvolmento", que, mesmo faltando uma sílaba, ainda é uma grande palavra para se memorizar a ordem dos fonemas (letras) e o número de sílabas. Também não faz sentido se uma palavra é com um "S" ou dois "S", como na palavra "confisão" (ou "confusão"?). Outro aspecto característico é o surdo lembrar as letras que constituem as palavras, porém trocar a posição delas, como no caso de "prescia". E, no caso de "apender", notamos, mais uma vez, a falta de apoio fonológico na escritura da LP como L2, uma vez que não oferece condições de o candidato saber que falta uma letra.

(B) Estrato lexicogramatical

Como estrato interno do sistema linguístico, o estrato lexicogramatical corresponde à gramática e ao léxico. Aqui serão consideradas as escolhas lexicais no subsistema da avaliatividade.

\begin{abstract}
A maneira como o produtor de um texto oral ou escrito se posiciona em relação ao seu leitor ou a seu interlocutor e a forma como julga o mundo concebido no texto que produz traz à tona diferentes tipos de avaliação. Tais avaliações evidenciam, em termos léxico-gramaticais, os tipos de atitudes negociadas no texto (VIAN JR., 2009, p. 100, grifo nosso).
\end{abstract}

Como justificamos anteriormente, torna-se difícil a análise em separado porque, mesmo quando apontamos aspectos lexicais e/ou gramaticais, estamos trabalhando com a semântica discursiva, em última instância.

Exemplos:

4- O GOVERNO DO BRASIL ESTA CADA VEZ PROBLEMA SOCIEDADE POIS ESTA AUMENTANDO OS IMPOSTOS DE COMIDA, CARRO, IPTU... ETC QUE ESTA INDO MUITO MAL DE CRESCIMENTO DE CORRUPÇÃO [...]. ATRASOU DE VERBA, ATRASOU DE PAGAMENTO DE BOLSAS. AGORA O BRASIL JÁ ESTA SENDO CRISE COMO CORRUPÇÃO E LAVAGEM JATO. (01 LLUFS/2016).

5- E muito difícil para aprender o português, precisar ir a escola todos os dias tiras as dúvidas também recursos, os professores entender os surdos e difícil para aprender a língua português, os professores ajudar como escrever $[\ldots]$. 


\section{Linguagens - Revista de Letras, Artes e Comunicação - ISSN 1981- 9943 \\ Blumenau, v. 12, n. 3, p. 456-473, set./dez. 2018. \\ DOI: http://dx.doi.org/10.7867/1981-9943.2018v12n3p456-473}

[...] os surdos tem vergonha não saber escrever o português nunca aprender o esforço, precisar ajudar os outros, e simples normal para os surdos aprender a língua português e libras, os professor poder ajudar os surdos crescer o futuro melhor, muito diferentes para eles aprender junto com os ouvinte ajudar os outros. (01 LLUFS/2015).

Através dos dois exemplos (4 e 5), temos acesso, por meio do estrato léxico-gramatical, a opiniões, sentimentos, atitudes dos candidatos. No exemplo 4, o Brasil é avaliado negativamente (apreciação) pelas razões enumeradas pelo candidato a partir de lexias negativas: "aumentando impostos", "crescimento da corrupção", "atraso de verbas para bolsas de estudo" etc. Se considerarmos a proposta de contexto para a GSF, o texto apresenta um contexto de situação (registro) caraterístico da escrita de LP como L2 de muitos surdos. Os significados do contexto cultural nos remetem ao que os membros da comunidade surda significam em leitura de mundo e isto nos orienta a entendermos que seus significados ideológicos (VIAN JR.; DE SOUZA, 2017).

No exemplo 05, pelo exigido na aplicação da prova, o candidato precisava desenvolver um texto defendendo se o ensino de língua portuguesa para surdos deveria sofrer adaptações ou se deveria ser ensinada sem adaptações. Segundo o candidato, "é muito difícil aprender português" (afeto, gradação) - esse é o seu sentimento. E denuncia que somente através da "cópia" e do "resumo" fica difícil os surdos aprenderem língua portuguesa, por isso "tem vergonha não saber escrever o português". Para o candidato, é preciso que haja profissionalismo e solidariedade - "os professor poder ajudar os surdos crescer o futuro melhor"; "eles aprender junto com os ouvinte ajudar os outros". As lexias escolhidas representam seu ponto de vista, e a gramática usada tem a ver com a dificuldade que é para os surdos, em vista da escolarização a que são submetidos, dominarem a norma culta da LP como L2. As pesquisas de Brochado (2003) e Neves (2017) discutem também estes mesmos aspectos.

\section{(C) Estrato semântico-discursivo}

O estrato semântico-discursivo é considerado o terceiro nível (VIAN JR., 2009), o do significado, e se encontra no nível da abstração, para além do fonema/letras (nível grafofonológico), do léxico-gramática (fraseado). Precisamos enfatizar aqui que o conceito de semântica na LSF envolve a pragmática, para Halliday (2017, p. 341): “[...] Y lo mismo con la 


\section{Linguagens - Revista de Letras, Artes e Comunicação - ISSN 1981- 9943 \\ Blumenau, v. 12, n. 3, p. 456-473, set./dez. 2018. \\ DOI: http://dx.doi.org/10.7867/1981-9943.2018v12n3p456-473}

pragmática: para mí, siempre fue sencillamente la finalidad de la semántica. No necesitamos una disciplina separada" ${ }^{10}$.

Para esse estrato, exporemos um exemplo para as temáticas de 2014, 2015 e 2017.

Exemplos:

6- 2014: temática sobre escola inclusiva ou bilíngue.

Surdos não tem condições inclusão escolar porque professores não língua de sinais também interprete nada, surdos esta triste tambem mal [...]

Escola Bilíngue surdos conseguir aprender desenvolvimento da língua brasileira de sinais, professores tem libras ensina alunos entenda ótima.

Surdos e já tinha as condições bilíngues, com salas em que sejam aprender a língua de sinais e o português escrito. bem !! (01 LL-UFS/2014).

7- 2015: Quanto ao ensino de LP para surdos: as estruturas de LP devem ser adaptadas ou devem ser ensinadas sem adaptações?

Segunda língua -L2 como sabia conhecimento porque, por isso era muito passado história a vida é surdo não entende mas precisa conhecio fundo que é prapria língua porteguesa precisa importante (01 LL-UFS/2015).

...muito passado não tenho interprente nada muito difícil como surdo aprender libras não é possível [...]

8- 2017: Educação à Distância.

O Educação de distância importantes faculdade difícil alguns e pesquisa coisa lá São Paulo mas aqui Sergipe faculdade tem aula só avisa vai São Paulo curso Horas 40 então Aproveitar aprender formar por que distância coisa informação alunos ah entender bem mas alguns mais profundo estudar esforço viajar estados visitar faculdade estudar pesado bom aprender depois voltar Sergipe [...] (01 LL-UFS/2017).

O que podemos identificar, de um modo geral, é que os surdos, desta pesquisa, não desenvolvem os textos de acordo com o tipo solicitado, no caso, o dissertativo-argumentativo. Geralmente, expõem algumas ideias, porém, às vezes, se torna um pouco difícil adentrar o viés semântico-discursivo, considerando-se que o texto é escrito segundo a gramática da Libras.

Uma das temáticas que melhor desenvolveram foi sobre a escola inclusiva ou bilíngue (exemplo 6), uma realidade que está bem próxima deles. Na escola inclusiva, queixam-se dos professores que não sabem sua língua como em "[...] porque professores não língua de sinais [...]”. Já o modelo de escola bilíngue é exaltado, considerando-se que os surdos seriam,

\footnotetext{
${ }^{10}$ Contexto geral da citação: "En cierto sentido, la única razón por la que esa tradición creó la sociolingüística y la pragmática fue, en primer lugar, porque no existían en la teoría del lenguaje, donde deberían haber estado. Y siempre dije que no necesitábamos el concepto de sociolingüística, porque nuestro concepto de lingüística siempre fue 'socio'. Y lo mismo con la pragmática: para mí, siempre fue sencillamente la finalidad de la semántica. No necesitamos una disciplina separada" // "De certo modo, a única razão pela qual a tradição criou a sociolinguística e a pragmática foi, em primeiro lugar, porque elas não existiam na teoria da linguagem, onde deveriam estar. E eu sempre disse que não precisávamos do conceito de sociolinguística, porque nosso conceito de lingüística sempre foi 'socio'. E o mesmo com a pragmática: para mim, sempre foi simplesmente o objetivo da semântica. Não precisamos de uma disciplina separada" (HALLIDAY, 2017, p. 341, tradução nossa) .
} 


\section{Linguagens - Revista de Letras, Artes e Comunicação - ISSN 1981- 9943 \\ Blumenau, v. 12, n. 3, p. 456-473, set./dez. 2018. \\ DOI: http://dx.doi.org/10.7867/1981-9943.2018v12n3p456-473}

primeiro, ensinados em sua língua materna "Escola Bilíngue surdos conseguir aprender desenvolvimento da língua brasileira de sinais [...]" e depois em LP para escrita “[...] aprender a língua de sinais e o português escrito [...]”. Sobre a educação bilíngue para surdos, vários pesquisadores argumentam acerca de sua importância na escolarização do Povo Surdo, advogando "a implantação de uma educação bilíngue para surdos, que defende que estes sujeitos devem interagir com interlocutores usuários de língua de sinais o mais precocemente possível” (LACERDA; LODI, 2009, p. 12).

O exemplo 7 traz algumas ideias sobre a situação da escolarização dos surdos numa tentativa de expor a importância da Libras e da língua portuguesa "prapria língua porteguesa precisa importante", porém não há claramente uma perspectiva argumentativa, nem exposição sobre a temática ou sobre se a LP deve ser adaptada ou ensinada sem adaptações. Os próprios textos motivadores da prova ajudariam a argumentar sob a perspectiva da adaptação, considerando-se que LP é L2 para surdos. Vejamos sobre os textos motivadores:

- O primeiro traz o decreto da Libras (BRASIL, 2005, p. 04): “Art. 13. O ensino da modalidade escrita da Língua Portuguesa, como segunda língua para pessoas surdas [...]”.

- O segundo, por sua vez, é um texto publicado por Nadal (2010), intitulado "O desafio de ensinar língua portuguesa a alunos surdos" que destaca a flexibilização de atividades e o investimento em experiências visuais.

- O terceiro, sob o título "Relações entre língua de sinais e língua portuguesa em materiais didáticos: a notação pelos números semânticos", tem o objetivo de "apresentar, de maneira simples e alternativa, que é possível alfabetizar a criança surda em sua segunda língua (L2) sem desnortear as estruturas da LP [...]" (DUARTE; PADILHA, 2012, p.310).

Como se pode acompanhar, foram dadas ao candidato informações sobre dois pontos de vista quanto ao assunto; porém, nenhum expôs sua opinião acerca de uma perspectiva ou de outra.

Por fim, consideraremos o exemplo 8 , no qual os dois textos motivadores são sobre o papel da Educação à Distância (EAD), evidenciando o papel da Universidade Federal de Santa Catarina (UFSC) na formação de surdos e ouvintes em cursos de Letras Libras na modalidade à distância. Os candidatos, de um modo geral, não identificaram esse tipo de educação. $\mathrm{O}$ candidato 01 LL-UFS/2017, por exemplo, associa o termo "distância" (da EAD) tanto fora do contexto de uso da proposta, pois fala da distância de Aracaju (cidade do exame) para São Paulo - “São Paulo curso Horas 40 [...] viajar estados visitar faculdade estudar pesado bom aprender 


\section{Linguagens - Revista de Letras, Artes e Comunicação - ISSN 1981- 9943 \\ Blumenau, v. 12, n. 3, p. 456-473, set./dez. 2018. \\ DOI: http://dx.doi.org/10.7867/1981-9943.2018v12n3p456-473}

depois voltar", quanto como o oposto a curso presencial, o que se infere a partir de "só avisa" (a vista - entendemos como presente, presencial). Ressaltamos que, provavelmente, eles não leram os textos motivadores, apoiando-se apenas na tradução em Libras, que traz o sinal de "distante".

Pelos exemplos analisados, aceita-se que a fragmentação em estratos responde apenas ao ponto de vista do analista porque a língua, principalmente em uso, não pode ser compartimentalizada. O significado se realiza pelo estrato léxico-gramatical, e este pelo estrato fonológico-fonético (ou gráfico). Assim, os planos do conteúdo e da expressão estão interrelacionados (HALLIDAY, 2017).

\section{CONCLUSÃO PARA O INACABADO}

Como pudemos comprovar no trabalho, A LSF está fundamentada em um modelo estratificado porque a linguagem é um sistema semiótico e, como tal, trabalha em diferentes níveis, do mais abstrato ao mais concreto:

El estrato semántico (el conjunto de significados que quieren expresarse) es realizado por el estrato lexicogramatical (el conjunto de palabras y sus combinaciones que se usan para expresar esos significados), que a su vez es realizado por el estrato fonológico (o grafológico) (el conjunto de marcas y sonidos físicos que se usan para expresar esas palabras y sus combinaciones) (HALLIDAY, 2017, p. 347, nota de rodapé do tradutor) ${ }^{11}$.

Quando nos referimos às produções de estudantes surdos de textos em LP como L2, muitas investigações e estudos ainda precisam ser arrolados porque, além de precisar seguir no ensino de LP como L2, é necessário considerar as características específicas de cada língua e de cada usuário. Os surdos, como usuários de uma língua gesto-visual, precisam ser ensinados com metodologia própria, a fim de que tenham acesso à leitura e à escritura de língua portuguesa. As pesquisas de Diniz e Pedrosa (2018), Neves (2017) e Brochado (2003) referendam esta perspectiva. Além do que esse posicionamento faz parte de uma política de respeito linguístico a grupos vulneráveis como a que propõe a ACD.

11 O estrato semântico (o conjunto de significados que se deseja expressar) é realizado pelo estrato lexicogramatical (o conjunto de palavras e suas combinações usadas para expressar esses significados), que por sua vez é realizado pelo estrato fonológico (ou grafológico) (o conjunto de marcas e sons físicos usados para expressar essas palavras e suas combinações). 
Defendemos, finalmente, que quem se propõe a ser analista crítico do discurso precisa expor como as práticas discursivas e sociais que sustentam as estruturas de uma sociedade estão fundamentadas: se englobando todos os seus cidadãos ou se são excludentes, velando estruturas de poder. Com isso, far-se-á jus ao termo "crítica" de seu nome, pois que ele se liga ao engajamento e compromisso social, tendo a ver com "atitude política e centrada na autocrítica" (PEDROSA, 2018, p. 123).

\section{REFERÊNCIAS}

BESSA, D. Análise de discurso crítica: história e perspectiva. In: KALLARRARI, Celso; BESSA, Décio; PEREIRA, Aline Santos (Orgs.). Estudos linguísticos e formação docente. São Paulo: Pontes, 2016. p. 115-142.

BONET, Juan Pablo. Reduction de las letras y arte para enseñar a ablar los mudos. 1620 . Disponível em: $<$ http://www.cervantesvirtual.com/obra/reduction-de-las-letras-y-arte-paraensenar-a-ablar-los-mudos-0/>. Recuperado em: 15 abr. 2019. Acesso em: 06 jan. 2019.

BOURDIEU, Pierre. O poder simbólico. 2. ed. Rio de Janeiro: Bertrand Brasil, 1998.

BRASIL. Decreto $n^{0}$ 5.626, de 22 de dezembro de 2005. Brasília. Disponível em: $<$ http://www.planalto.gov.br/ccivil_03/_ato2004-2006/2005/decreto/d5626.htm>. Acesso em: 06 jan. 2019.

BRASIL. Decreto no 9.465, de 02 de janeiro de 2019. Brasília. Disponível em: $<$ http://www.in.gov.br/materia/-/asset_publisher/Kujrw0TZC2Mb/content/id/57633286>. Acesso em: 18 maio 2019.

BROCHADO, S. A apropriação da escrita por crianças surdas usuárias da língua de sinais brasileira. Tese de Doutorado. Universidade Estadual Júlio de Mesquita Filho, UNESP, São Paulo, 2003. Disponível em:

$<$ https://repositorio.unesp.br/handle/11449/102476>. Acesso em: 06 jan. 2019.

DINIZ, Debora Moreno; PEDROSA, Cleide. Estudos identitários e escritura em língua portuguesa como 12 em redação de vestibular de surdos. Relatório final de IC, bolsista do CNPq, UFS, SE - Brasil, 2018.

DUARTE, Anderson Simão; PADILHA, Simone de Jesus. Relações entre língua de sinais e língua portuguesa em materiais didáticos: a notação pelos números semânticos. ReVEL, v. 10, n. 19, 2012. Texto adaptado e disponível em: <www.revel.inf.br>. Acesso em: 12 fev. 2014.

FAIRCLOUGH, Norman. Discurso e mudança social. 2. ed. Tradução de Izabel Magalhães. Brasília: Editora Universidade de Brasília, 2008. 


\section{GALLAUDET, E. M. American and European systems of deaf-mute instruction compared. s.1.: New Englander, 1868.}

GARÉ, R. M. R. Educação formal x educação não formal: diferentes práticas de ensino e a construção de identidades surdas. São Paulo: Gregory, 2016.

GHIO, Elsa; FERNÁNDEZ, María Delia. Manual de lingüística sistémico funcional: el enfoque de M. A. K. Halliday \& R. Hasan - aplicaciones a la lengua española. Santa Fe: Universidad Nacional del Litoral, 2005.

HALliDAY, M. A. K. Obras esenciales de M. A. K. Halliday. Compilado por Elsa Ghio, Federico Navarro e Annabelle Lukin. Traducción de: Elsa Ghio et ál. 1. ed. Libro digital, PDF (Ciencia y Tecnología). Santa Fe: Ediciones UNL, 2017.

LACERDA, Cristina; LODI, Ana Claudia. A inclusão escolar bilíngue de alunos surdos: princípios, breve histórico e perspectivas. In: LOIDI, Ana Claudia; LACERDA, Cristina Broglia. Uma escola, duas línguas: letramento em língua portuguesa. 2009. p. 11-32.

NADAL, Paula. O desafio de ensinar Língua Portuguesa a alunos surdos. Recuperado de $<$ https://novaescola.org.br/conteudo/1533/o-desafio-de-ensinar-lingua-portuguesa-a-alunossurdos $>$. Acesso em: 09. jan. 2020.

NEVES, Bruna Crescêncio. Educação bilíngue para surdos e as implicações para o aprendizado da Língua Portuguesa como segunda língua. Tese (Doutorado em Linguística). Universidade Federal de Santa Catarina. Florianópolis, 2017.

PEDROSA. Análise Crítica do Discurso no PPGL: pesquisas e contribuições sociais. In: RAMALHO, C. B.; LIMA, G. de O. S. (Orgs.). Estudos Linguísticos e Literários: Edição comemorativa 10 anos do Programa de Pós-Graduação em Letras da UFS. Aracaju: Criação, 2018. p. 153-178.

PEDROSA. Análise crítica do discurso e a proposta da corrente nacional: da abordagem às primeiras pesquisas. In: KALLARRARI, Celso; BESSA, Décio; PEREIRA, Aline Santos (Orgs.). Estudos linguísticos e formação docente. São Paulo: Pontes, 2016. p. 69-100.

PEDROSA. Análise Crítica do Discurso: do linguístico ao social no gênero midiático. 1. ed. Aracaju: EDUFS, 2008.

RAMÍREZ CARRIÓN, Manuel. Maravillas de Naturaleza en que se contienen dos mil secretos de cosas naturales, dispuestos por abecedario a modo de Aforismos fáciles, y breves, de mucha curiosidad y provecho, recogidos de la lección de diversos, y graves Autores. Córdoba: Imprenta de Francisco García, 1629. Disponível em:

$<$ https://bvpb.mcu.es/va/consulta/registro.cmd?id=400916>. Acesso em: 16 jul. 2019.

ROCHA, Solange. O INES e a educação de surdos no Brasil: aspectos da trajetória do Instituto Nacional de Educação de Surdos em seu percurso de 150 anos. 2. ed. V. 1. Rio de Janeiro: INES, 2008. 
SILVA, S. G. de L da. Compreensão leitora em segunda língua de surdos sinalizantes da língua de sinais. Tese (Doutorado em Linguística). Universidade Federal de Santa Catarina. Florianópolis. 2016.

SOFIATO, Cássia Geciauskas; REILY, Lucia Helena. "Companheiros de infortúnio": a educação de "surdos-mudos" e o repetidor Flausino da Gama. Revista Brasileira de Educação, Universidade Estadual de Campinas, v. 16, n. 48, p. 625-640, set.-dez. 2011.

STROBEL, Karin. História da Educação de Surdos. Florianópolis: UFSC, 2009.

SOUSA, A. N. Educação plurilíngue para surdos: uma investigação do desenvolvimento da escrita em português (segunda língua) e inglês (terceira língua).Tese (Doutorado em Linguística).Universidade Federal de Santa Catarina, Florianópolis, 2015.

VAN DIJK, T. Discurso e poder. Organização de Judith Hoffnagel e Karina Falcone. São Paulo: Contexto, 2008.

VIAN JR., O.; DE SOUZA, M. M. Linguística Sistêmico-Funcional e suas contribuições à pesquisa linguística no contexto brasileiro. Revista Odisseia, v. 2, p. 185-203, 20 dez. 2017. Disponível em: < https://periodicos.ufrn.br/odisseia/article/view/12887/9024>. Acesso em: 10 jun. 19.

VIAN JR., O. O sistema de avaliatividade e os recursos para gradação em língua portuguesa: questões terminológicas e de instanciação. Appraisal system and graduation resources in Brazilian Portuguese: terminological and instantiation issues. D.E.L.T.A., v. 25, n. 1, p. 99129, 2009.

VIEIRA, Josenia Antunes; MACEDO, Denise Silva. Conceitos-chave em análise de discurso crítica. In: BATISTA JR., J. R. L.; SATO, D. T. B.; MELO, I. F de. (Orgs.). Análise de discurso crítica para linguistas e não linguistas. 1. ed. São Paulo: Parábola, 2018. p. 48-77.

WODAK, Ruth; MEYER, Michael. Análise Crítica do Discurso: História, Agenda, Teoria e Metodologia. In: WODAK, Ruth; MEYER, Michael (Orgs.). Métodos de análise crítica do discurso. 3. ed. atual. e mod. Londres: Sage, 2009. p. 1-33. 